\title{
GCU
}

Glasgow Caledonian

University

University for the Common Good

\section{Why buy an album? The motivations behind recorded music purchases}

Brown, Steven Caldwell; Knox, Don

Published in:

Psychomusicology: Music, Mind and Brain

DOI:

10.1037/pmu0000134

Publication date:

2016

Document Version

Author accepted manuscript

Link to publication in ResearchOnline

Citation for published version (Harvard):

Brown, SC \& Knox, D 2016, 'Why buy an album? The motivations behind recorded music purchases',

Psychomusicology: Music, Mind and Brain, vol. 26, no. 1, pp. 79-86. https://doi.org/10.1037/pmu0000134

\section{General rights}

Copyright and moral rights for the publications made accessible in the public portal are retained by the authors and/or other copyright owners and it is a condition of accessing publications that users recognise and abide by the legal requirements associated with these rights.

Take down policy

If you believe that this document breaches copyright please view our takedown policy at https://edshare.gcu.ac.uk/id/eprint/5179 for details of how to contact us. 


\title{
APA copyright notice: This article may not exactly replicate the final version published in the APA journal. It is not the copy of record.
}

\author{
Psychomusicology: Music, Mind and Brain journal home page: \\ http://www.apa.org/pubs/journals/pmu/?tab=2
}

\section{Why Buy an Album? The Motivations Behind Recorded Music Purchases}

\author{
Steven Caldwell Brown, School of Philosophy, Psychology and Language Sciences, University of \\ Edinburgh
}

Don Knox, School of Engineering and Built Environment, Glasgow Caledonian University

\begin{abstract}
The present study examined why music fans choose to buy recorded music given the multitude of other ways to listen to music without payment. A sample of 135 participants ( $68.88 \%$ female) with a mean age of 29.05 years completed an open-ended questionnaire. These written responses were analyzed thematically. Two key themes were identified: Short-term comparisons and Long-term considerations. Motivations focused on value-maximization across both themes, with short-term comparisons including how many songs were liked on an album and the pros and cons of different formats. Price was by far the biggest factor. Long-term considerations were more sophisticated, with wider motivations including where money goes, and a consideration of recording artists' financial position. Some participants mentioned as a factor how long an album would be enjoyed, thus betraying the nature of music as an experience good. The desire to add to a music collection was an important consideration. The findings suggest that what might drive people toward music piracy is not the perceived costliness of music but rather a perception of poor value for money. Discussion focuses on how the recorded music industry can make legal purchases of recorded music more attractive than illegal counterparts.
\end{abstract}

Keywords: decision making, music purchasing, digital revolution, willingness to pay, thematic analysis

There has been little research into the motivations behind recorded music purchases, despite recorded music sales dropping steadily in the past decade. It is thought that widespread music piracy has played a critical role in this shift. Though $39 \%$ of revenues in the recorded music industry now come from digital services, physical formats still account for over half of all global revenues (IFPI, 2014). Furthermore, research shows that while so-called second generation (on-demand services) are taking over, most people still possess a physical music collection and actively listen to digital 
collections (Liikanen \& Åman, in press). Of interest in the present study, is why individuals continue to buy music, given they no longer need to in order to listen to their favorite songs.

\section{The Recorded Music Industry and the Digital Revolution: A Brief Overview}

The music industry has undergone huge changes over the past decade, as a direct result of the digital revolution. In particular, practices in the distribution and promotion of recorded music have changed from conventional purchases of albums and singles in different physical formats to digital formats via the Internet.

Pioneering peer-to-peer file-sharing service, Napster is largely responsible for setting digital downloads into motion, which facilitated widespread music piracy on a global scale. Released in 1999, Napster demonstrated how quickly and easily music could be uploaded and downloaded on the Internet as well as the potential for digital music distribution to be profitable. Though music piracy has existed for decades, it is the digitization of recorded music that has inspired widespread copyright infringement of protected works on an unprecedented scale. The true prevalence of music piracy remains unknown (as with all crime), but conservative estimates of Internet users actively downloading copyrighted media illegally tend to cluster around one third of the global population (see Bustinza, Vendrell-Herrero, Parry, \& Myrthianos, 2013). Antipiracy measures to date have largely failed, with pirates adapting well to technical and legislative changes-Higgins and Marcum (2011) explain that knowledgeable Internet users always seem to outsmart new technologies faster than they can be produced. In recent years, the most effective antipiracy measure appears to be the rise of increasingly more attractive legal alternatives to digital piracy. As the late former Apple CEO Steve Jobs stated: "You'll never stop [piracy], what you can do is compete with it" (quoted in Goodell, 2003). Indeed, the iPod was released soon after Napster boomed, quickly followed by the iTunes store. Apple remains the market leader on digital music.

The emerging preference for digital music has altered how music fans consume and enjoy recorded music, where over 80 legal modes of accessing digital music now exist in the United Kingdom, in addition to illegal means. Music can now be bought on a track-by-track basis, streamed via subscription services such as Spotify or Deezer, or listened to on-demand from personal collections stored in cloud services (networked online storage of data), to name but a few options. As much as the digitization of music, increased access to the Internet along with the increased capabilities of smartphones have shaped new listening behaviors. Music listening can now meet particular needs such as aiding a workout at the gym or managing the hectic lifestyle of living in busy urban cities. The popularity of music streaming via music subscription services calls into question what it now means to own music.

While there has been a renewed interest in vinyl, largely thanks to the likes of Record Store Day (where artists release exclusive content), The International Federation of the Phonographic Industry (IFPI) in 2013 reported a steady increase in global digital revenue from music annually since 2008. IFPI notes that subscription services are now a central part of the recorded music market, with 20 million paying subscribers worldwide in 2012-an increase of $44 \%$ on 2011. In this light, different music formats can rest alongside one another, serving different functions. 


\section{Impact of Technology on Music-Listening Practices}

Research from the field of Music Psychology has been particularly valuable in measuring the impact of the digital revolution, with recent findings showing that the majority of music listening occurs via computers (Greasley \& Lamont, 2011) and that the shuffle function of MP3-players is particularly popular (Krause \& Hargreaves, 2013). While Heye and Lamont (2010) suggest that use of the shuffle functioning may be indicative of one's engagement with technology, Batt-Rawden and DeNora (2005) suggest it can be used to keep one's music collection novel, by avoiding "overlistening." Krause and Hargreaves reveal active use of shuffle, playlist functions and so forth, and that the more control that technology allows encourages more complex patterns of music listening. A quarter of all songs listened to on Spotify are also skipped in the first five seconds (Guardian Music, 2014), which highlights that consumers are not simply listening to anything. However, with music readily available everywhere and all of the time, it can be said to be less "special." Lamere (2006) observed that $64 \%$ of the average collection of 3,500 songs on participants' i-Tunes had never been played. Probing further the implications of Lamere's findings, it is unlikely that such songs would have been paid for where Holt and Copes (2010) confirm from qualitative enquiry that so-called "music pirates" often do not watch or listen to all of the content they download.

Perhaps most noteworthy, is that technology has ultimately created different types of consumer. Lamont and Webb (2010) defined two distinct types of music listener: the "magpie" and the "squirrel." Magpies were noted to listen to a restrictive volume of favorite songs with squirrel listeners having relatively larger catalogues and able to more easily recall music from such catalogues without needing to directly experience it. Elsewhere, Molteni and Ordanini (2003) defined five unique groups of music downloader including Occasional, Explorers, Mass listeners, Duplicators, and Curious. Such findings highlight that music-listening practices have diversified in light of varying methods of accessing music.

Adopting a qualitative approach, Nuttall et al. (2011) identified different "tribes" of music listener. These include loyalists, experience seekers, preachers, conventionalists, revolutionists, and techys. These different groups, though demonstrating unique characteristics (techys, e.g., were found to be concerned with sound quality, unlike other groups), often shared similar traits. Legal consumption of music was common among conventionalists and loyalists, for instance; experience seekers, preachers, revolutionists, and techys were more likely to consume music illegally. More recently, Parry, Bustinza, and Vendrell-Herrero (2012) defined four unique music consumer types: explorative consumer, early adopters, cautious consumer, and band fan, whose music consumption patterns also varied. There is some overlap between Nuttall et al.'s "tribes," with band fans, for example, equivalent to loyalists.

\section{How Piracy Has Affected Recorded Music-Listening Practices}

Several studies have considered whether piracy engagement acts as a substitute for otherwise legal purchases of recorded music. Oberholzer-Gee and Strumpf (2010) summarize such works, commenting that: "Some studies find evidence of a substitution effect, other findings, in particular 
the papers using actual file-sharing data, suggest that piracy and music sales are largely unrelated" (p. 49). Indeed, the findings from different studies vary dramatically mainly as a consequence of the difficulty in measuring actual piracy behaviors. Common methods include economic modeling (a simplified theoretical construct that explains relationships between variables, quantitatively) and self-report measures. The latter is particularly unreliable given its inability to accurately define actual volumes of piracy engagement. Social desirability is also an issue (see Brown, 2014).

What is clear, is that those who download illegally also spend more money on music legally (Huygen et al., 2009; Watson, Zizzo, \& Fleming, 2015; Zentner, 2006) than individuals who do not otherwise engage in music piracy. Schwarz (2014), reviewing research into this area, acknowledges that it is now uncontroversial that individuals engaging in digital piracy (or filesharers, in his words) are greater consumers of culture overall. If music pirates are in fact also buying more music, then it may not be wise for the music industry to marginalize them. Though in legal terms they are breaching copyright, in economic terms they may be contributing more money to the recorded music industry than those who do not engage in piracy.

\section{Why Buy Recorded Music?}

The benefits of owning music are common sense, where it is desirable to be able to listen to your favorite music when you want, while supporting your favorite musicians. It is only now, with widespread music piracy, that the antecedents to recorded music purchasing deserve attention. With widespread access to digital music in various formats, both legally and otherwise, music fans need not own music to be able to listen to it on demand.

Much research in this area explores reasons not to buy recorded music. Watson et al. (2015) support the consistent findings from empirical works (in their review of over 200 sources) that individuals engaging in digital piracy (various forms of piracy, not just music) are most likely to be young males. Findings regarding age may be influenced by younger people listening to music more than older populations (Bonneville-Roussy, Rentfrow, Xu, \& Potter, 2013). In their timely review, Watson et al. find that individuals are likely to engage in digital piracy, as it allows to sample new/niche content, is free, and that peers also engage in this activity. Barriers to piracy engagement include technical aspects, such as availability of legal alternatives and the perceived technical risks involved in obtaining media illegally. Moral beliefs were also found to correlate negatively with piracy engagement.

Exploring motivations on CD purchases, North and Oishi (2006) researched both British and Japanese samples. Informed from interviews, a follow-up questionnaire demonstrated that over $50 \%$ of the variance in explaining CD purchasing decisions could be accounted for by five factors: friendship (such as recommendations from friends); need to control and be involved with music (music preferences and convenience); music industry (heard it in record store or magazine); need to reexperience music; and interaction with media (heard it on TV or radio).

Other research has considered why individuals choose to purchase recorded music. Notably, McIntyre (2011) and Nuttall et al. (2011), both from Cockrill (2011), offer unique insights into the prepurchase motivations of recorded music. McIntyre, exploring generational differences, concludes 
that: "Baby boomer records shop-buyers and Generation $Y$ downloaders exhibit key generational identity differences in intrinsic meanings, values and associations inherent within their differential music transactional processes" (p. 150). Ultimately reflecting on individuals born between 1945 and the early 1960s, and those born from the 1980s onward, the findings raise important questions over the importance of owning physical products. This is of particular relevance, as conventional brickand-mortar record stores struggle to attract consumers. Ownership was compulsory for older generations to listen to music on demand, but that is of course no longer the case.

Nuttall et al. (2011) explore music consumption through focus group discussion. Ownership was not found to be a strong motivating factor, where participants demonstrated guilt-free piracy behaviors. With CDs noted to only contain a few songs that are liked, the desirability of the album format is called into question; this is especially so given music subscription services emphasize personalized playlists. The authors also observed themes including the effect of fan loyalty on attitudes and downloading behaviors. Such findings, in addition to recent research that demonstrates that how best to distribute music depends largely on what "stage in the game" an artist is at (David, 2010; Regner, Barria, Pitt, \& Neville, 2009), exposes one of the many difficulties in successfully selling recorded music to a largely segmented marketplace.

\section{Study Overview and Research Questions}

Reflecting on how technology has impacted on music-listening behaviors, the present research aims to explore the unique motivations behind recorded music purchases, given ownership of music is no longer necessary to be able to listen to music on demand. Exploratory in nature, the research also aims to benefit literature on music piracy by exploring reasons not to pirate music. By simply asking participants why they engage in a particular (legal) behavior, much can be learned from the responses that are not discolored from any biases concerning the loaded word piracy. Furthermore, there is also relatively little research of a qualitative nature in this area, with qualitative studies to date (such as Holt \& Copes, 2010; McIntyre, 2011; Moore \& McMullan, 2009; Nuttall et al., 2011) providing invaluable and revealing findings. It is clear from these studies that participants are willing to disclose intimate knowledge about their music-listening habits. Using this more flexible qualitative approach, new areas of interest can be identified that will benefit not only research into music piracy but also related consumer aspects of music-listening behavior during a period of rapid change.

\section{Methodology}

\section{$\underline{\text { Participants }}$}

Convenience sampling was employed, with a final sample of 135 participants providing data used in the analysis. Participants were recruited using email subscriptions and online research websites. There were 40 males and 95 females, with a mean age of 29.05 years (SD 10.40). The age range was 50 (16 - 66 years). Over half $(52.59 \%)$ of the sample was from the European Union, with $36.30 \%$ from North America. The remainder of the sample (11.11\%) were from other continents. With regards to employment status, $40.74 \%$ of the sample were employed (part-time or fulltime), $51.11 \%$ were students, and $1.48 \%$ were retired (three participants did not respond to this question). 


\section{$\underline{\text { Design and Procedure }}$}

A qualitative research design was utilized, modeled on Lonsdale and North (2011), with participants completing an open-ended questionnaire. Participants were asked: "What are the most important considerations when deciding whether or not to purchase recorded music?" They were given three text boxes to outline these considerations. The text boxes allowed for lengthy responses (though the majority of responses were one or two sentences long), and the methodology ensured a standardization of responses (Braun \& Clarke, 2013) yet with participants still given complete control over their responses, as would have been the case in traditional interview or focus group settings. Three separate text boxes were purposefully included to encourage different reasons.

Three hundred and fifty four valid open-ended responses ( $87.41 \%$ of a possible 405$)$ were collapsed into categorical variables for subsequent thematic analysis. This analytical approach was chosen given its flexibility (needed, in anticipating a large variation in responses), which would be readable for various audiences and suitable for informing policy development (Braun \& Clarke, 2006).

\section{Results}

In accordance with the "phases of thematic analysis" proposed by Braun and Clarke (2006), themes were identified further to examination of participants' responses, reviewing common patterns in the dataset. Initially, the pattern of responses suggested that recorded-music purchases all stemmed from seeking to maximize value, and though this persisted through subsequent revisions, more subtle differences became apparent upon closer inspection. Consequently, two broad themes were identified as motivating purchases of recorded music: Short-term comparisons and Long-term considerations. While Braun and Clarke note that: "More instances do not necessarily mean the theme itself is more crucial" (p. 82), several initial themes (such as the potential for viruses and whether or not the music was legal) were dropped, as they were not considered representative overall, with only individuals specifying such motivations (such responses are considered in the Discussion section). Despite analysis conforming to qualitative conventions, the relative volume of responses concerning the pattern of results is considered relevant. Accordingly, and as with Lamont's (2011) research (into strong musical experiences), using the same methodology, the percentages of different responses is presented (see Figure 1, below). Both short-term comparisons and long-term considerations are included, and in some instances merged.

As can be seen in Figure 1, motivations behind recorded music purchases varied widely, with the majority of responses concerning value maximization. All quotes below in italics are direct quotes from participants, as are those in double quotation marks in the main body.

\section{Short-Term Comparisons}

The most prominent theme (over two thirds of all responses) among participants' various motivations for purchasing recorded music was Short-term comparisons. Or, put simply, decisions made based on immediately available information, which would appear the same to anyone, such as the number of songs on an album or the audio quality of a particular format. These are therefore 
fixed. This also lends credence to the large percentage of participants reporting such motivations. Many participants simply stated their desire to know the origin of the music (including not only the artist, but in many instances the record label) along with the availability and functionality of the music. Importantly, participants demonstrated comparisons between different formats as a means to reach decisions.

By far the biggest motivation on whether or not to purchase recorded music was the price, accounting for a quarter of all responses. While most participants provided brief responses such as "the price" or "the cost," many of the price-related reasons put forward concerned the comparison between the price of different formats. The awareness of different formats suggests music purchasing as a planned activity, not impulsive.

Is it worth it to buy the album than to download online?

Is the CD good value for money?

The quality of the music also emerged as a key consideration for many of the participants, suggesting a market for remastered versions of albums and higher quality music downloads. Once more, the majority of responses were not particularly revealing, with "quality" and "recording quality" being frequent responses: this is a likely outcome given the methodology employed (see also Discussion section, below). The responses do also suggest that purchases of recorded music are, once more, largely planned, and that participants were making comparisons in other to reach decisions.

Is it good quality?

Quality of recording, i.e. is it a live recording or studio?

Format emerged as another major concern, where both the cost and quality of music will be dependent on its format. An awareness of the many ways in which music can be accessed was evident from responses such as "What formats are available?" and "Availability elsewhere (for a better price)". The perceived benefits of different formats were also expressed, revealing that music purchasing is to some extent utilitarian.

Physical experience: I enjoy opening up a $C D$, reading the cover notes, etc.

\section{Can I get it for free on spotify?}

Another important consideration in determining whether or not to purchase recorded music was the number of songs appearing on an album, not the duration of an album. This is a particularly interesting observation, where it is only in the past decade that consumers been able to readily hear individual songs from an album ahead of purchase (aside from stand-alone singles). The implication of this, and different pricing strategies, is that the volume of songs on a recording (only one participant cited "length") is used by consumers as a proxy of judging whether or not value maximization will be achieved on a given purchase. Once again, the methodological nature of recorded music purchasing is demonstrated, suggesting an evaluation of costs and benefits.

How many tracks do I actually like on considered album 


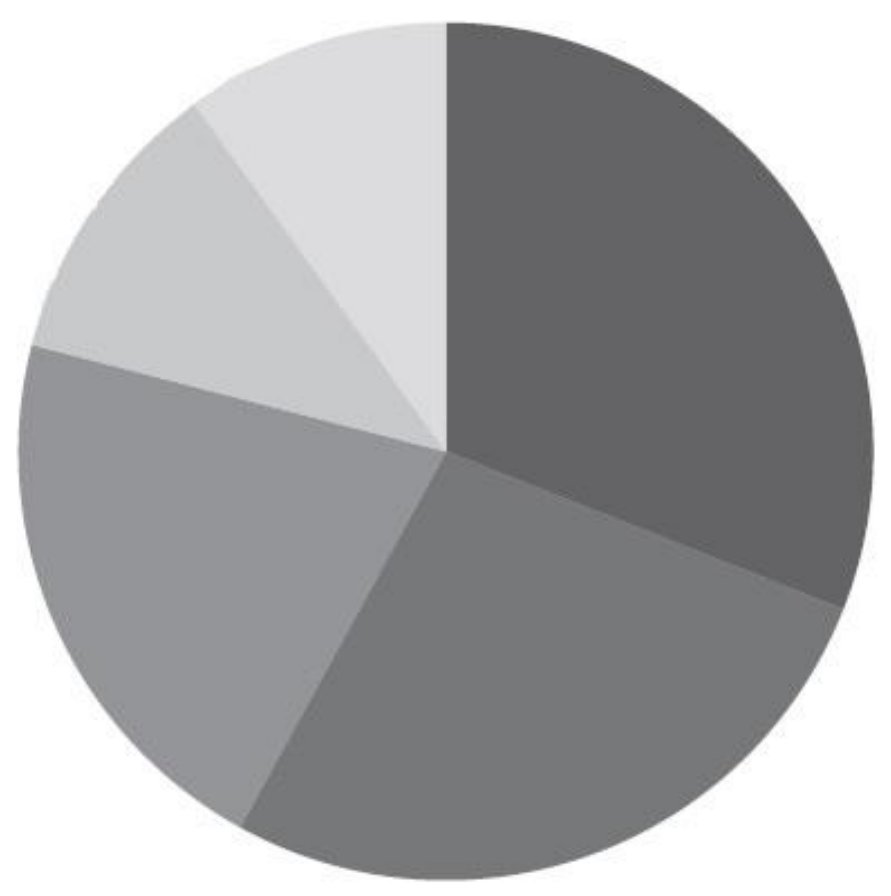

No. of liked songs and perceived length of time music will be enjoyed

Cost related issues including consideration of artists' financial position

Issues over music format and audio quality

Desire to add music to collection

\section{Other reasons}

Figure 1. Five broad motivation categories for purchasing recorded music.

\section{Long-Term Considerations}

The second broad theme that was identified (representing approximately a third of all responses) was decision-making aspects, which did not directly reflect the music itself, but rather subjective qualities of the consumer. As such, the responses were varied. This theme captured what could be considered more sophisticated judgments, which demand a broader decision-making process, taking into account a variety of longer-term factors.

The desire to add a particular piece of music to a music collection (of bought music) was identified as a key driver for many participants, with most participants commenting on their enjoyment of the music itself as a key factor. The question that emerges, however, is what motivations occur upon hearing music by an unknown band and if they are different in any way. No insights are offered from the data analyzed. The excerpts below also raise questions, unanswered by the data analyzed.

Whether I want the music in my collection (rather than just listening on the radio)

What I want to add to my collection 
Related to this is the finding that a large proportion of participants actively aim to anticipate how long the music will be listened to. In the same way that the volume of songs on a recording appears to serve as a useful indicator of whether or not value will be achieved with a purchase of recorded music, participants also forwarded notions of the perceived longevity that music would have in their lives. As an experience good (that is, the music must first of all be experienced before it can be enjoyed), it is of interest that music would be thought of in such a capacity, where perhaps the previous speculative risk of buying an album outright has become a dated concept, with so many ways in which to listen to music nowadays. Given there is no reliable way to anticipate how long a particular song or collection of songs will be enjoyed, such comments may reflect participants' reconstructions of value on previous purchases.

Do I like it enough to listen to it repeatedly?

How long it will take me to get bored with the music?

While recommendations from friends and the popularity of the music positions music listening in a social context, the relatively small number of responses to this end do not reveal the decisionmaking process of purchasing recorded music to be particularly motivated by social influences (though one participant did state "I do not want to be questioned for owning it"). Given the clear consideration over an artists' financial position (demonstrated above), it is unclear if popularity is used to distinguish between whether or not artists are considered as worthy of being paid or if their popularity is used to motivate purchase as a means of demonstrating fan worship with an eye to perhaps maintaining group membership. Certainly for some participants, friends' recommendations was an important factor and recent research (Krause, North, \& Heritage, 2014) into the integration of music listening features into Facebook reveals how they are used for communicative and personal reasons, including promoting a particular group and expressing one's identity.

\section{How popular the artist is}

\section{Friends' recommendation}

A wider consideration that highlights the broadest level of thought concerns the monetary position of the recording artist - this echoes previous findings (including Nuttall et al., 2011) relating to the perceived financial wealth of musicians as discouraging legal music purchases. As one participant in Yu's (2012) qualitative study explains: "I do not think music piracy is a crime. I do not think they (the singers) need two Ferraris" (p. 368). While some participants expressed a desire to "support the artist," others were more interested in the specifics of their financial position: the two contrasting excerpts below are insightful and demonstrate the planned nature of recorded music purchases, both centering on the income of artists.

Is the artist making a living or are they filthy rich?

Royalties (musicians have to make a living)

\section{Discussion}


Adopting a thematic analysis of self-reported motivations for purchasing recorded music, two themes were identified: Shortterm comparisons and Long-term considerations. In doing so, the research has shown that a careful assessment of the price of recorded music is at play and that a variety of cognitive evaluations present music-purchasing as methodical, and for the most part, informed by the relative costs and benefits of different music formats. This is likely the result of the ever-expanding variety of ways in which to purchase music (legally or otherwise). Notably, only one participant commented on the legality of music being a determinant factor, and the comment from another participant concerning the potential for viruses is suggestive of a considered approach when seeking out music illegally as the risk of viruses is far greater when downloading music illegally. Research finds that the fear of viruses is a deterrent against music piracy (Bachmann, 2011; Sheehan, Tsao, \& Pokrywczynski, 2012).

Greenberg et al. (2015) argue that when listening to a new song, it only takes a few seconds to decide whether or not to buy it. Certainly, the present findings suggest that a number of quick cues are taken into consideration, focused on value for money. The cost of the music itself emerged as the single most important factor, corroborating research into piracy motivations (including Watson et al., 2015). Expanding on research in this area, results suggest that the cost is not the driving factor but rather the perceived value, with particular attention paid to music in different formats to help establish this value. Explored elsewhere (Brown, 2011), value can be manipulated in various ways and in the present study, many participants expressed the benefits of physical recordings which are offered by remastered and rereleased versions of albums. Related to this, the format and quality of recorded music were also forwarded as key components in the decision-making process. The perceived benefits of different music formats reveal that participants actively make the most of different ways of listening to music, and are not necessarily reliant on one particular music format. Indeed, new formats need not replace one another but can readily complement each other, offering consumers different things; the recent revival of vinyl and the fact that most paid-for music is still sold in physical formats (IFPI, 2014) suggests that the digital revolution is in fact more of a digital evolution.

The reasons explored above reveal the planned nature of recorded music purchasing, predominantly taking into consideration various comparisons. Nowhere was this more marked than with participants' attention to how many songs on an album are liked. A critical observation, the data reflect the relatively recent trend of being able to hear (in a variety of ways) new albums before they are released, allowing consumers to "try before they buy." As such, the findings confirm the importance of allowing music fans to sample music before they commit to a purchase, revealing the positive contribution of legal music streaming services such as Spotify and Deezer which reduce the speculative risk of buying an album outright (see Dang Nguyen, Dejean, \& Moreau, 2012). How many songs are liked on an album is not something that can be understood until an album has been sampled, multiple times. Also, in principle, if the number of liked songs is a critical determinant in choosing to purchase music, then singles ought to be the favored medium given $100 \%$ of the songs will be liked. Recent digital trends suggest this might be the case.

The second theme that was discovered reveals that more personal motivations also play a role in influencing recorded music purchases. Notably, a desire to support artists was a key motivator for many participants and relatedly, that a perception that musicians are wealthy might discourage purchasing their music legally. Building on literature that demonstrates that piracy affects artists 
differently (Bachache, Borreau, \& Moreau, in press; Hammond, 2012), the present findings suggest that consumers perception of how financially successful an artist is will affect their willingness to pay for their music. How this perception is formed, remains unknown (see also Limitations, below), but certainly Green, Sinclair and Tinson (in press) discovered that the perception of the music industry being wealthy justified engagement in music piracy.

A desire to add a piece of music to a music collection was also noted, suggesting an ongoing relationship with particular artists. The desire to support artists appears to contradict the aforementioned consideration of an artists' financial status. However, it could be that music fans are keen to support their favorite bands, at any cost, or put an emphasis on newer artists who are not superstars. With investment not only of money but time in creating and maintaining record collections, continued purchasing of new releases by favorite bands is likely for those individuals who already have are a record collection. In Nuttall et al.'s (2011) words, describing "loyalists," explain how new releases are: "Bought on blind faith without reviewing them first" (p. 158). In their qualitative study, Nuttall et al. found that fan loyalty affected attitudes and downloading behavior with participants explaining they buy music legally as they "owe" it to their favorite artist. The implication, however, is that in the absence of fan loyalty, younger generations familiar with illegal downloading are less likely to be motivated to buy music to add to their (nonexisting) physical "collections." As Wikstrom (2012) notes: "When a music consumer is able to download hundreds of songs in a few seconds (without paying) and to keep thousands of songs on their laptops, the concept of the once cherished and carefully selected record collection crumbles" (p. 9). Furthermore, with music-listening now becoming more eclectic (with single-song downloads from different artists, e.g.), it may be more difficult to maintain so-called collections other than on digital devices, which are dynamic in nature.

Interestingly, participants were observed as striving for value maximization by estimating how long a particular piece of recorded music would be enjoyed. Related to the consideration of how many songs are liked on a particular album, such a finding runs counter intuitive to music as an experience good (Regner \& Barria, 2009), further demonstrating the planned nature of recorded music purchases. This observation illustrates a reluctance to buy music outright, contravening conventional wisdom over how pleasure is evaluated. What indexes are used to determine if an album is likely to be enjoyed over a long period of time is something that must be considered in detail if it is to be fully understood.

Friends' recommendations were also noted to influence the decision-making process surrounding recorded music purchases. While this was the primary factor of North and Oishi's (2006) study (one of the few to specifically explore themes related to the present study), only a small number of participants in the present study forwarded such reasons as motivating them to buy recorded music. This contrast may perhaps reflect the intervening rise in popularity of digital music where music is predominantly consumed and enjoyed anonymously, purchased over networked devices or listened to via headphones on the move. And yet, music streaming services such as Spotify actively encourage "sharing" of listening episodes via social networking website Facebook, for example.

In summary, the sample demonstrated traits that fit the template of the "cautious consumer" (Parry et al., 2012). Free versions of subscription services may appeal to such individuals, where musicstreaming services are in fact designed to act as music discovery platforms. They are able to 
inform consumers with the knowledge of how many "good" songs are on an album, for example. Hardy (2012), however, notes how music-streaming services are not being used in this way but rather as substitutes for other forms of paid-for music listening. As such, and with artists routinely pulling their catalogues from Spotify and other services, accepted practices for royalties must be negotiated for music subscription services to prosper. Certainly, participants in the present study demonstrated concern over where their money goes when choosing to buy music, not just a simple unwillingness to pay for music. With more ways to listen to recorded music than ever before, including over 500 legal digital services worldwide (IFPI, 2013) (as well as an untold number of sources to engage in illegal downloading online), the future guise of recorded music will unquestionably be predominantly digital. IFPI reports that subscription services are now vital to the recorded music industry, with 20 million paying subscribers worldwide in 2012. Spotify is the second greatest source of digital music revenue in Europe, and in Finland, Sweden and Norway, the greatest. Ingham (2013) reports that 30\% of income for "European indies" now comes from these streaming services.

\section{Recommendations for Future Research}

Returning once more to North and Oishi's (2006) now dated research that defined friendship and the need to control and be involved with the music as the greatest predictor of $C D$ purchasing, future research could explore predictors of digital music purchases using similar methodologies, given new modes of music listening such as music streaming have risen to prominence. Furthermore, a systematic evaluation of the different benefits of music across different formats could facilitate promotion of recorded music to a largely segmented marketplace. By doing so, the wealth of options available can be streamlined to target different consumers. To this end, research into what persuaded individuals formerly engaging in music piracy to adopt legal alternatives would benefit policymakers greatly, where anecdotally, it is believed that improved legal alternatives are responsible for increased digital music revenue, not the successes of antipiracy measures. On a related note, more cross-cultural research may reveal why music listening preferences vary across different countries and shed light on the relative successes of different legislative approaches to tackling digital piracy.

Given the observations on the appearance of musicians as wealthy as a factor in minimizing the likelihood of paying for music legally, future research could ascertain how evaluations are formed regarding a musicians' perceived wealth, if at all. It is entirely possible it is more of an excuse rather than a reason to neutralize the guilt associated with obtaining music illegally. Consistent findings highlight how individuals engaging in music piracy use techniques of neutralization (Sykes \& Matza, 1957) to justify their behaviors. Copes (2003) notes that for techniques of rationalization to be truly applicable, it is first necessary for the individual to believe that there is something wrong with their behavior, and it would certainly appear from research to date such as Bonner and O'Higgins (2010) that individuals engaging in music piracy do regard their behaviors as immoral. As outlined in Brown (2013), the most common technique is the "denial of injury," with music piracy appearing as a victimless crime. 


\section{Limitations}

As a qualitative study, the potential for bias must be recognized. Particularly, due to the relative brevity of responses due to the data collection method, the responses are lacking the richness found in most qualitative studies, including those reviewed in this article. The methodology nonetheless remains appropriate for the aims of the study, which was to collect a sufficient volume of responses to the central question in order to make generalizations. However, the data only provide a descriptive account of why people choose to buy recorded music. A theoretical framework in which to interpret the results would help situate the findings in relation to other works. One such theory is uses and gratifications theory (see Krause et al., 2014). Rooted in the sociopsychological tradition, it informs an approach to understand why and how people seek out particular types of media to meet specific needs. With little known of the sample, a more specific form of sampling would have been useful. One which targets those who routinely engage in music piracy might have been particularly useful from a policy point of view, shedding light on the decision-making processes behind choosing which music to buy legally.

\section{Concluding Remarks}

The emerging ubiquity of digital music exposes a significant shift in how music fans consume and enjoy recorded music. In his 2015 book "How Music Got Free," Witt poses the question: "If something was available for free, and could be freely and infinitely reproduced for free, with no degradation in quality, why would anyone pay to own it for a second time, when they already had it, for free?" (p. 125). This question is commonly posed in popular media, and is likely one that consumers will ask themselves when confronted with the option to buy music, rather than stream it or download it illegally. This study finds several reasons why people buy music that they can figuratively "own" without having paid for, including a desire to fund their favorite artists, or not, depending on a perception of musicians perhaps being wealthy and so undeserving of financial reward. Overall, the study emphases that music fans now "shop around." More dedicated research into when CDs are selected over digital formats, streaming over radio, and so forth, will help establish the full extent of the cultural and commercial impact of the digital revolution, with consumers now armed with a wealth of music listening choices to satisfy a range of needs and wants. More dedicated research in this vein may the benefit the music industry, whose recent efforts to appease shifting consumer preferences may prove to be the most effective antipiracy strategy to date.

\section{References}

Bachache-Beauvallet, M., Borreau, M. and Moreau, F. (2015). Piracy and Creation: The Case of the Music Industry. European Journal of Law and Economics, 39(2), 245-262.

Bachmann, M. (2011). Suing the genie in the bottle: The failed RIAA Strategy to Deter P2P Network Users. In K. Jaishankar (Ed.), Cyber criminology: Exploring Internet crimes and criminal behavior. Boca Raton, FL: CRC Press, Taylor and Francis Group. 
Batt-Rawden, K., \& DeNora, T. (2005). Music and informal learning in everyday life. Music Education Research, 7, $289-304$.

Bonner, S., \& O'Higgins, E. (2010). Music piracy: Ethical perspectives. Management Decision, 48, 1341-1354.

Bonneville-Roussy, A., Rentfrow, P. J., Xu, M. K., \& Potter, J. (2013). Music through the ages: Trends in musical engagement and preferences from adolescence through middle adulthood. Journal of Personality and Social Psychology, 105, 703-717.

Braun, V., \& Clarke, V. (2006). Using thematic analysis in psychology. Qualitative Research in Psychology, 3, 77-101.

Braun, V., \& Clarke, V. (2013). Successful qualitative research: A practical guide for beginners. London, England: Sage.

Brown, S. C. (2011). Artist autonomy in a digital era: The case of Nine Inch Nails. Empirical Musicology Review, 6, $198-213$.

Brown, S. C. (2013, July). Digital piracy and the moral compass. The Psychologist, 26, 538 -539.

Brown, S. C. (2014). Approaches to digital piracy research: A call for innovation. Convergence, 20, $129-139$.

Bustinza, O. F., Vendrell-Herrero, F., Parry, G., \& Myrthianos, V. (2013). Music business models and piracy. Industrial Management \& Data Systems, 113, 4-22.

Cockrill, A. (Ed.). (2011). The future of music retailing [Special issue]. Journal of Retailing and Consumer Services, 18, 119-166.

Copes, H. (2003). Societal attachments, offending frequency, and techniques of neutralization. Deviant Behavior: An Interdisciplinary Journal, 24(2), 101-127.

Dang Nguyen, G., Dejean, S., \& Moreau, F. (2012, March). Are streaming and other music consumption modes substitutes or complements? (Working paper 2025071). Retrieved from http://ssrn.com/ abstract2025071

David, M. (2010). Peer to peer and the music industry. London: Sage. Goodell, J. (2003, December). Steve Jobs: The rolling stone interview. Retrieved from www.rollingstone.com

Greasley, A. E., \& Lamont, A. (2011). Exploring engagement with music in everyday life using experience sampling methodology. Musicae Scientiae, 15, 45-71.

Green, T., Sinclair, G. and Tinson, J. (2015). Do they Know it's CSR at all? An Exploration of Socially Responsible Music Consumption. Journal of Business Ethics, 1-16 (ONLINE FIRST - SEE http://dx.doi.org/10.1007/s10551-015-2582-8)

Greenberg, D. M., Baron-Cohen, S., Stillwell, D. J., Kosinksi, M., \& Rentfrow, P. J. (2015). Musical Preferences are Linked to Cognitive Styles. PLoS One, 10, e0131151. 
Guardian Music. (2014, May). One-quarter of Spotify tracks are skipped in first five seconds, study reveals. Retrieved from http://www.theguardian .com/music/2014/may/07/one-quarter-of-spotifytracks-are-skipped-infirst-five-seconds-study-reveals Retrieved May 132014.

Hammond, R. G. (2012, March) Profit leak? Pre-release file sharing and the music industry. (Working paper 2059356). Retrieved from http:// ssrn.com/abstract2059356

Hardy, P. (2012). Download! How the Internet transformed the record business. London: Omnibus Press.

Heye, A., \& Lamont, A. (2010). Mobile listening situations in everyday life: The use of mp3 players while traveling. Musicae Scientiae, 14, 95-120.

Higgins, G. E., \& Marcum, C. D. (2011). Digital Piracy: An Integrated Theoretical Approach. Durham, NC: Carolina Academic Press.

Holt, T. J., \& Copes, H. (2010). Transferring Subcultural Knowledge On-Line: Practices and Beliefs of Persistent Digital Pirates. Deviant Behavior, 31, 625- 654.

Huygen, A., Rutten, P., Huveneers, S., Limonard, S., Poost, J., Leenheer, J., . . .. Helberger, N. (2009, February). Ups and downs: Economic and cultural effects of file sharing on music, film and games. Retrieved from http://www.ivir.nl/publicaties/vaneijk/Ups_And_Downs_authorised_translation.pdf Retrieved April 122012.

Ingham, T. (2013, May). Streaming now earns more than downloads for third of EU indies. Retrieved from www.musicweek.com

International Federation of the Phonographic Industry. (2013, February). IFPI Digital Music Report 2013: Engine of a Digital World. Retrieved from http://www.ifpi.org/content/section resources/dmr2013.html Retrieved February 272013.

International Federation of the Phonographic Industry. (2014, March). IFPI digital music report 2014. Lighting up new markets. Retrieved from http://www.ifpi.org/downloads/Digital-Music-Report2014.pdf Retrieved March 202014.

Krause, A. E., \& Hargreaves, D. J. (2013). myTunes: Digital music library users and their self-images. Psychology of Music, 41, 531-544.

Krause, A. E., North, A. C., \& Heritage, B. (2014). The uses and gratifications of using Facebook music listening applications. Computers in Human Behavior, 39, 71-77.

Lamere, P. (2006). Re: What's on your iPod? [Web log message]. Retrieved from http://blogs.sun.com/plamere/entry/what s on your ipod

Lamont, A. (2011). University students' strong experiences of music: Pleasure, engagement, and meaning. Musicae Scientiae, 15, $229-249$.

Lamont, A., \& Webb, R. (2010). Short- and long-term musical preferences: What makes a favorite piece of music? Psychology of Music, 38, 222-241. 
Liikanen, L.A. and Åman, P. (2015). Shuffling Services: Current Trends in Interacting with Digital Music. Interacting With Computers, 1-20 [ONLINE FIRST - SEE http://iwc.oxfordjournals.org/content/early/2015/03/27/iwc.iwv004.abstract)

Lonsdale, A. J., \& North, A. C. (2011). Why do we listen to music? A uses and gratifications analysis. British Journal of Psychology, 102, $108-134$.

Mclntyre, C. (2011). News from somewhere: The poetics of Baby Boomer and Generation Y music consumers in tracking a retail revolution. Journal of Retailing and Consumer Services, 18, 141-151.

Molteni, L., \& Ordanini, A. (2003). Consumption patterns, digital technology and music downloading. Long Range Planning, 36, $389-406$.

Moore, R., \& McMullan, E. C. (2009). Neutralizations and rationalizations of digital piracy: A qualitative analysis of university students. International Journal of Cyber Criminology, 3, 441- 451.

North, A. C., \& Oishi, A. (2006). Music CD Purchase Decisions. Journal of Applied Social Psychology, 36, 3043-3084.

Nuttall, P., Arnold, S., Carless, L., Crockford, L., Finnamore, K., Frazier, R., \& Hill, A. (2011). Understanding music consumption through a tribal lens. Journal of Retailing and Consumer Services, 18, 152-159.

Oberholzer-Gee, F., \& Strumpf, K. (2010). File Sharing and Copyright. In J. Lerner \& S. Stern (Eds.), Innovation Policy and the Economy (Vol. 10, pp. 19 -55). Chicago, IL: University of Chicago Press.

Parry, G., Bustinza, O., \& Vendrell-Herrero, F. (2012). Servitisation and value co-production in the UK music industry: An empirical study of Consumer Attitudes. International Journal of Production Economics, 135, $320-332$.

Regner, T., \& Barria, J. A. (2009). Do consumers pay voluntarily? The case of online music. Journal of Economic Behavior and Organization, 71, 395- 406.

Regner, T., Barria, J. A., Pitt, J., \& Neville, B. (2009). An Artist life-cycle model for digital media content: Strategies for the light web and the dark web. Electronic Commerce Research and Applications, 8, $334-342$.

Schwarz, J. A. (2014). Online file sharing: Innovations in media consumption. New York, NY: Routledge.

Sheehan, B., Tsao, J., \& Pokrywczynski, J. (2012). Stop the music! How advertising can help stop college students from downloading music illegally. Journal of Advertising Research, 52, 309 -321.

Sykes, G., \& Matza, D. (1957). Techniques of neutralization: A theory of delinquency. American Sociological Review, 22, $664-670$.

Watson, S. J., Zizzo, D. J., \& Fleming, P. (2015). Determinants of Unlawful File Sharing: A Scoping Review. PLoS One, 10, e0127921. 
Wikstrom, P. (2012). A typology of music distribution models. International Journal of Music Business Research, 1, 7-20.

Witt, S. (2015). How music got free. London, England: The Bodley Head.

Yu, S. (2012). College Students' Justification for Digital Piracy: A Mixed Methods Study. Journal of Mixed Methods Research, 6(4), 364-378.

Zentner, A. (2006). Measuring the effect of file sharing on music purchases. The Journal of Law \& Economics, 49, 63-90. 